\title{
Predictors of renal recovery in patients with pre-orthotopic liver transplant (OLT) renal dysfunction
}

\author{
Jose Iglesias ${ }^{1,2,3^{*}}$, Elliot Frank ${ }^{4}$, Sushil Mehandru 3 , John M Davis ${ }^{5}$ and Jerrold S Levine ${ }^{6,7}$
}

\begin{abstract}
Background: Renal dysfunction occurs commonly in patients awaiting orthotopic liver transplantation (OLT) for end-stage liver disease. The use of simultaneous liver-kidney transplantation has increased in the MELD scoring era. As patients may recover renal function after OLT, identifying factors predictive of renal recovery is a critical issue, especially given the scarcity of available organs.

Methods: Employing the UNOS database, we sought to identify donor- and patient-related predictors of renal recovery among 1720 patients with pre-OLT renal dysfunction and transplanted from 1989 to 2005. Recovery of renal function post-OLT was defined as a composite endpoint of serum creatinine $(\mathrm{SCr}) \leq 1.5 \mathrm{mg} / \mathrm{dL}$ at discharge and survival $\geq 29$ days. Pre-OLT renal dysfunction was defined as any of the following: $\mathrm{SCr} \geq 2 \mathrm{mg} / \mathrm{dL}$ at any time while awaiting OLT or need for renal replacement therapy (RRT) at the time of registration and/or OLT.

Results: Independent predictors of recovery of renal function post-OLT were absence of hepatic allograft dysfunction, transplantation during MELD era, recipient female sex, decreased donor age, decreased recipient ALT at time of OLT, decreased recipient body mass index at registration, use of anti-thymocyte globulin as induction therapy, and longer wait time from registration. Contrary to popular belief, a requirement for RRT, even for prolonged periods in excess of 8 weeks, was not an independent predictor of failure to recover renal function post-OLT.

Conclusion: These data indicate that the duration of renal dysfunction, even among those requiring RRT, is a poor way to discriminate reversible from irreversible renal dysfunction.
\end{abstract}

\section{Background}

Renal dysfunction occurs commonly in patients with end-stage liver disease (ESLD) awaiting orthotopic liver transplantation (OLT) [1,2]. In the MELD (Model EndStage Liver Disease) scoring era, the use of simultaneous liver-kidney transplantation (SLKT) has increased [3,4]. From a renal standpoint, considerable uncertainty remains as to which patients will benefit from SLKT [4]. In many cases, pre-OLT renal dysfunction is ameliorated by OLT $[5,6]$. Moreover, in patients with ESLD and renal dysfunction, studies evaluating factors predictive of

\footnotetext{
* Correspondence: jiglesias23@gmail.com

'Department Medicine subsection of Nephrology, UMDNJ School of

Osteopathic Medicine, Stratford, NJ 08084, USA

${ }^{2}$ Department of Medicine subsection Nephrology, Jersey Shore University

Medical Center Neptune, Neptune, NJ, USA

Full list of author information is available at the end of the article
}

recovery of renal function and/or or risk factors predictive of non-recovery of renal function post-OLT have yielded conflicting results $[4,7]$.

Several factors complicate the decision whether patients should receive SLKT. Most important is the complex interaction between the liver and kidney. The cirrhotic milieu often leads to dramatic reductions in renal perfusion, so that renal dysfunction in the setting of cirrhosis may reflect prerenal factors rather than intrinsic renal damage. In the case of prerenal dysfunction, OLT should lead to nearly full recovery of renal function. While a renal biopsy can easily distinguish between prerenal and intrinsic causes for renal insufficiency, the coagulopathy associated with cirrhosis frequently precludes performing a biopsy $[1,8-10]$. These issues are highlighted by the paucity of pathological data in nearly all studies of the hepatorenal syndrome (HRS) [11,12].

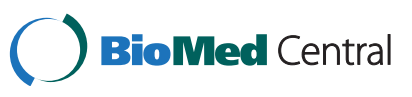


Given the scarcity of available donor renal allografts, identifying which patients with pre-OLT renal dysfunction will regain renal function post-OLT becomes an even more critical issue. Previous studies have been hampered by small population sizes, single center experiences, and the retrospective nature of the data $[8,10]$. Employing the UNOS database, we sought to identify donor- and patient-related predictors of renal recovery and non-recovery in 1720 patients with pre-OLT renal dysfunction and transplanted from 1989 to 2005. In this cohort, the most important independent predictor of recovery of renal function post-OLT was an absence of hepatic allograft dysfunction. Other predictors of renal recovery were related to amelioration or reversal of the cirrhotic milieu and/or improved renal perfusion, as reflected by decreased severity of recipient liver disease and a lack of use of calcineurin inhibitors, respectively. An intriguing finding of our study is the potentially beneficial effect of anti-thymocyte globulin induction, which emerged as an independent predictor of renal recovery distinct from its calcineurin inhibitor-sparing effects. Finally, contrary to popular belief, our data suggest that the requirement for renal replacement therapy, even for prolonged periods in excess of 8 weeks, may not be an independent predictor of the failure to recover renal function post-OLT.

\section{Methods}

\section{Ethics statement}

The study was undertaken in accordance with principles of the Declaration of Helsinki and the standards of good clinical practice. The study was approved by the Institutional Review Board and Ethics Committee (IRB\#06008) of Barnabas Health Community Medical Center.

\section{Study population}

The current study was designed as a retrospective cohort study. Data were obtained the United Network for Organ Sharing (UNOS) for donors and OLT recipients transplanted from January, 1989, through March, 2005, the time of creation of our database. Recovery of renal function following OLT was defined as a primary composite end point of a serum creatinine $(\mathrm{SCr}) \leq 1.5 \mathrm{mg} / \mathrm{dL}$ at discharge and survival of $\geq 29$ days. Patients included in our analysis were those who possessed pre-OLT renal dysfunction, defined as any of the following: (1) $\mathrm{SCr}$ $\geq 2 \mathrm{mg} / \mathrm{dL}$ at any time while awaiting OLT; (2) need for renal replacement therapy (RRT) at the time of registration (dialysis at time of registration); (3) need for RRT at time of OLT (dialysis at time of transplant); (4) need for RRT at time of both registration and OLT (dialysis-dependence). Patients were excluded from analysis if they received multi-organ transplantation, were $<17$ years old at the time of OLT, or received a living-related or living- unrelated OLT. In addition, patients were excluded if their $\mathrm{SCr}$ was $\leq 1.5 \mathrm{mg} / \mathrm{dL}$ at the time of OLT and they had received RRT neither at the time of registration nor at the time of OLT. Data on the type of RRT, whether intermittent or continuous, were not available.

\section{Data collection}

Data collected for OLT recipients included the following: routine demographic variables (age, sex, race); wait time from registration; registration and/or peri-transplant severity of illness characteristics (body mass index [BMI]; intensive care unit [ICU] admission; presence of ascites, hepatic encephalopathy, or portal vein thrombosis [PVT]; need for mechanical ventilation, transjugular intrahepatic portosystemic shunt [TIPS], or RRT); comorbidities (coronary artery disease, diabetes mellitus, hypertension, peripheral arterial disease, cachexia); etiology of ESLD (fulminant hepatic failure, hepatitis $\mathrm{B}$, hepatitis $\mathrm{C}$, non-alcoholic chronic steatohepatitis [NASH], alcoholic cirrhosis, or other); registration and/or peri-transplant physiologic variables (clotting times, serum albumin, liver enzymes, total bilirubin); MELD score; cold and warm ischemia times; occurrence of allograft dysfunction; and immunosuppressive medications used for induction and/ or maintenance therapy (antithymocyte globulin, OKT3, basiliximab, daclizumab, alemtuzumab, cyclosporine, tacrilimus, sirolimus). Immunosuppressive usage was reported for the immediate post-OLT period, before recovery of renal function could occur. Renal variables collected for OLT recipients included the requirement for RRT, SCr, and estimated glomerular filtration rate (eGFR) at the times of registration, OLT, and discharge. For patients receiving RRT, several values of SCr were used, an unadjusted and two adjusted values. The unadjusted $\mathrm{SCr}$ was the value entered into the UNOS database. Given uncertainty whether the entered $\mathrm{SCr}$ was obtained pre- or post-dialysis, analysis was repeated using a single adjusted value for $\mathrm{SCr}$ of either 4.0 or $5.0 \mathrm{mg} / \mathrm{dL}$. The former value is in accord with previous work by Bahirwani et al.[13] eGFR was determined using the 4-variable equation of the Modification of Diet in Renal Disease (MDRD) study group. Data collected for donors included age, sex, race, BMI, terminal liver enzymes, terminal total bilirubin, and whether the OLT derived from a non-heart beating donor. Transplant related data include type of induction therapy, initial immunosuppression, cold ischemia time, warm ischemia time and liver allograft function.

\section{Data analysis}

All statistical analyses unless otherwise indicated were performed as a comparison for OLT recipients who recovered renal function vs. those who did not. Summary statistics were computed for the two cohorts, those with recovery of renal function and those with non-recovery. 
Continuous variables were expressed as mean \pm standard deviation and compared by the Student $t$ test or the Wilcoxon rank-sum test. For purposes of statistical analysis, patients receiving RRT were assigned a $\mathrm{SCr}$ of $4 \mathrm{mg} / \mathrm{dL}$. Categorical variables were compared by Fisher's exact test or chi-square analysis. Comparison of cohorts included both univariate and multivariate analyses. Candidate variables for multivariate analysis included all variables found to be significantly different by univariate analysis at $\mathrm{p}<0.05$. To determine variables independently predictive of renal recovery, we performed logistic regression analysis with forward variable selection. Stepwise selections for logistic regression were based on the maximum likelihood ratio. For continuous variables, the odds ratio (OR) represents the relative amount by which the probability of observing recovery of renal function increases or decreases if the independent variable is increased by exactly one unit. OR and their 95\% confidence intervals (CI) were determined by exponentiation of the regression coefficient or its upper and lower $95 \% \mathrm{CI}$, respectively.

\section{Results}

Univariate analyses of factors associated with nonrecovery of renal function post-OLT within the entire cohort

To determine factors associated with recovery vs. nonrecovery of renal function following OLT, we analyzed multiple routinely available demographic, clinical, and laboratory variables obtained in OLT recipients with pre-OLT renal dysfunction who were transplanted between 1989 and 2005.

A total of 1720 patients were evaluated. 863 (51\%) patients recovered renal function, while 857 (49\%) failed to recover renal function. Notably, of those who recovered renal function, 500 (58\%) received RRT at some time prior to OLT. Of these, 79 (16\%) were on dialysis only at the time of registration, $252(50 \%)$ were on dialysis only at the time of OLT, and 169 (34\%) required RRT throughout their time on the waiting list. A similar distribution was seen for those who failed to recover renal function. 570 (67\%) required RRT at some time prior to OLT. 99 (17\%) were on dialysis only at the time of registration, 267 (47\%) were on dialysis only at the time of transplant, and 204 (36\%) required RRT throughout their time on the waiting list. Figure 1 depicts the percentage of patients with recovery vs. non-recovery of renal function according to their need for RRT at the time of registration and/or OLT.

Using our entire cohort $(n=1720)$, we compared OLT recipients with recovery vs. non-recovery of renal function by univariate analysis for multiple characteristics, including the following: recipient demographic variables and clinical characteristics at both the time of registration and the time of transplant (Table 1); recipient co-morbidities (Table 2); etiology of ESLD (Table 3); common laboratory chemistries

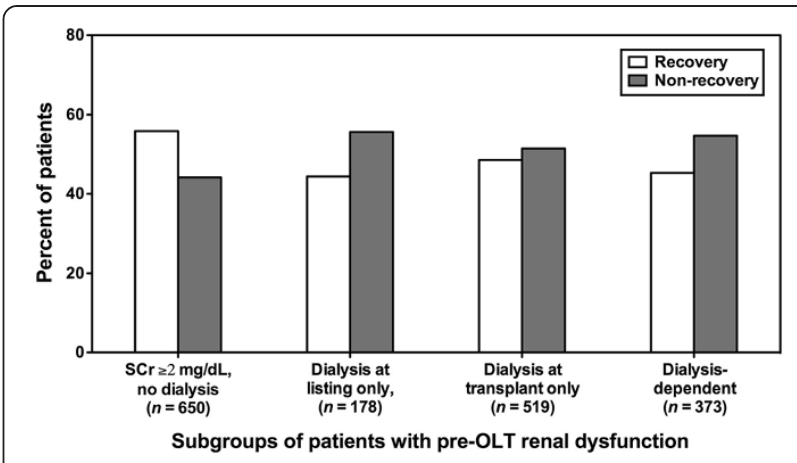

Figure 1 Recovery versus non-recovery of renal function following orthotopic liver transplantation (OLT) in patients with pre-OLT renal dysfunction grouped according to their need for renal replacement therapy (RRT). Recovery of renal function following OLT was defined as a composite end point of a serum creatinine $(\mathrm{SCr}) \leq 1.5 \mathrm{mg} / \mathrm{dL}$ at discharge and survival of $\geq 29$ days. Patients included in our analysis were those who possessed pre-OLT renal dysfunction, defined as any of the following: (1) $\mathrm{SCr} \geq 2 \mathrm{mg} / \mathrm{dL}$ at any time while awaiting OLT, but not requiring RRT ( $\mathrm{SCr} \geq 2 \mathrm{mg} /$ $\mathrm{dL}$, no dialysis); (2) need for RRT at registration, but not at OLT (dialysis at registration only); (3) need for RRT at OLT, but not at registration (dialysis at transplant only); (4) need for RRT at both registration and OLT (dialysis-dependent).

(Table 4); MELD score and allograft-related factors (Table 5); immunosuppressive regimen (Table 6); and donor demographic variables and clinical features (Table 7).

The following recipient-related demographic and clinical characteristics were associated with recovery of renal function post-OLT (Table 1): female sex $(\mathrm{p}<0.05)$; lack of ICU admission at the time of registration $(p=0.007)$; lack of need for mechanical ventilation either at the time of registration $(\mathrm{p}=0.00001)$ or at the time of OLT $(\mathrm{p}=0.015)$; absence of PVT at the time of OLT $(p=0.025)$; lack of need for RRT at the time of registration ( $p=0.003)$, at the time of OLT ( $p=0.01)$, or at both times $(p=0.03)$; a longer time on the waiting list $(\mathrm{p}=0.00001)$; and a lower BMI either at the time of registration $(p=0.019)$ or at the time of OLT $(\mathrm{p}=0.02)$.

OLT recipients who recovered renal function were more likely to be receiving their first OLT $(p=0.007)$ and to have no history of variceal bleeding $(\mathrm{p}=0.032)$ (Table 2$)$. The etiology of their ESLD was less likely to be fulminant hepatic failure $(\mathrm{p}=0.039)$ or NASH $(\mathrm{p}=0.04)$ (Table 3$)$. They were also less likely to have an elevated alanine transaminase (ALT) $(\mathrm{p}=0.007)$ (Table 4).

Recovery of renal function was associated with an absence of allograft dysfunction in the immediate post-OLT period $(p=0.00001)$ and with transplantation during the MELD era $(\mathrm{p}=0.0001)$ (Table 5). Aspects of the immunosuppressive regimen also correlated with the likelihood of renal recovery. Recovery of renal function was associated 
Table 1 Demographic, listing, and peri-transplant characteristics in patients with pre-OLT renal dysfunction that are associated with recovery of renal function post-OLT

\begin{tabular}{|c|c|c|c|c|}
\hline & Recovery of renal function $(n=863)$ & Non-recovery $(n=857)$ & $\mathrm{p}$ & OR $(95 \% \mathrm{Cl})$ \\
\hline \multicolumn{5}{|l|}{ Demographic characteristics } \\
\hline Age & $50.3 \pm 10.2$ & $50.0 \pm 10.5$ & 0.3 & \\
\hline Sex (male) & $544(63 \%)$ & $581(67 \%)$ & 0.043 & $0.81(0.66-0.98)$ \\
\hline Race (Caucasian) & $599(70 \%)$ & $620(72 \%)$ & 0.21 & $0.88(0.70-1.07)$ \\
\hline \multicolumn{5}{|l|}{ Listing characteristics } \\
\hline ICU admission & $207(24 \%)$ & $255(29 \%)$ & 0.007 & $0.74(0.60-0.92)$ \\
\hline Mechanical ventilation & $108(13 \%)$ & $172(20 \%)$ & 0.00001 & $0.57(0.43-0.74)$ \\
\hline Encephalopathy & $510(59 \%)$ & $541(60 \%)$ & 0.35 & $1.08(0.9-1.3)$ \\
\hline Ascites & $593(72 \%)$ & $598(63 \%)$ & 0.60 & $0.95(0.75-1.16)$ \\
\hline TIPS & $57(6.6 \%)$ & $63(7 \%)$ & 0.63 & $0.92(0.65-1.30)$ \\
\hline PVT & $17(1.9 \%)$ & $30(3.5 \%)$ & 0.052 & $0.55(0.32-0.93)$ \\
\hline Dialysis (at listing)* & $248(28 \%)$ & $303(32 \%)$ & 0.003 & $0.63(0.50-0.76)$ \\
\hline BMI $\left(\mathrm{kg} / \mathrm{m}^{2}\right)$ & $27.6 \pm 5.5$ & $28.4 \pm 6.1$ & 0.02 & \\
\hline \multicolumn{5}{|l|}{ Peri-transplant characteristics } \\
\hline Wait time from listing (days) & $178 \pm 297$ & $145 \pm 266$ & 0.00001 & \\
\hline ICU admission & $441(51 \%)$ & $417(49 \%)$ & 0.76 & $1.03(0.85-1.20$ \\
\hline Mechanical ventilation & $206(24 \%)$ & $249(29 \%)$ & 0.015 & $0.76(0.62-0.95)$ \\
\hline Encephalopathy & $34340 \%)$ & $344(41 \%)$ & 0.86 & $0.98(0.81-1.20)$ \\
\hline Ascites & $580(67 \%)$ & $547(64 \%)$ & 0.14 & $1.20(0.95-1.40)$ \\
\hline TIPS & $75(8.6 \%)$ & 79 (9.2\%) & 0.70 & $0.93(0.67-1.30)$ \\
\hline PVT & $22(2.5 \%)$ & $39(4.5 \%)$ & 0.025 & $0.55(0.32-0.99)$ \\
\hline Dialysis (at transplant)* & $421(49 \%)$ & $471(55 \%)$ & 0.01 & $0.70(0.57-0.85)$ \\
\hline Dialysis (at both listing and transplant) & $169(19 \%)$ & $204(23 \%)$ & 0.03 & $0.78(0.62-0.99)$ \\
\hline BMI $\left(\mathrm{kg} / \mathrm{m}^{2}\right)$ & $27.0 \pm 6.4$ & $28.0 \pm 6.3$ & 0.019 & \\
\hline
\end{tabular}

Abbreviations: BMI body mass index, $C I$ confidence interval, ICU intensive care unit, OLT orthotopic liver transplant, OR odds ratio, PVT portal vein thrombosis, TIPS transjugular intrahepatic porto-systemic shunt.

* The number of patients on dialysis at listing $(n=551)$ includes those on dialysis only at listing $(n=178)$ as well as those on dialysis at both listing and transplant $(n=373)$. Similarly, the number of patients on dialysis at transplant $(n=892)$ includes those on dialysis only at listing $(n=519)$ as well as those on dialysis at both listing and transplant $(n=373)$.

with use of antithymocyte globulin as an induction agent $(\mathrm{p}=0.014)$ and absence of use of tacrolimus $(\mathrm{p}=0.029)$ (Table 6).

With respect to donor-related factors (Table 7), recovery of renal function occurred more frequently in recipients whose allografts came from younger donors $(p=0.00001)$ and donors with a smaller BMI $(\mathrm{p}=0.007)$.

Finally, OLT recipients who recovered renal function post-OLT had lower SCr and higher eGFR both at the time of registration $(\mathrm{p}=0.00001)$ and at the time of transplant

Table 2 Co-morbidities in patients with pre-OLT renal dysfunction associated with recovery of renal function post-OLT

\begin{tabular}{|c|c|c|c|c|}
\hline & Recovery of renal function $(n=863)$ & Non-recovery $(n=857)$ & $p$ & OR $(95 \% \mathrm{Cl})$ \\
\hline Coronary artery disease & $9(1 \%)$ & $12(1.3 \%)$ & 0.66 & $0.68(0.30-1.50)$ \\
\hline Diabetes mellitus & $204(24 \%)$ & $235(27 \%)$ & 0.07 & $0.84(0.70-1.00)$ \\
\hline Hypertension & $158(18 \%)$ & $167(19 \%)$ & 0.53 & $0.90(0.72-1.17)$ \\
\hline Peripheral arterial disease & $7(0.8 \%)$ & $9(1 \%)$ & 0.56 & $0.74(0.27-2.00)$ \\
\hline Chronic obstructive pulmonary disease & $4(0.5 \%)$ & $11(1.3 \%)$ & 0.07 & $0.38(0.14-1.12)$ \\
\hline Re-transplantation & $136(16 \%)$ & $178(21 \%)$ & 0.007 & $0.70(0.56-0.90)$ \\
\hline Variceal bleeding & $66(7.7 \%)$ & $91(11 \%)$ & 0.032 & $0.70(0.50-0.97)$ \\
\hline Cachexia & $218(25 \%)$ & $228(26 \%)$ & 0.52 & $0.93(0.75-1.15)$ \\
\hline
\end{tabular}

Abbreviations: $\mathrm{Cl}$ confidence interval, OLT orthotopic liver transplantation, OR odds ratio. 
Table 3 Etiology of end-stage liver disease in patients with pre-OLT renal dysfunction associated with recovery of renal function post-OLT

\begin{tabular}{lllll}
\hline & Recovery of renal function $(\mathbf{n}=\mathbf{8 6 3})$ & Non-recovery $(\mathbf{n}=\mathbf{8 5 7})$ & $\mathbf{p}$ & $\mathbf{O R}(\mathbf{9 5 \%} \mathbf{C l})$ \\
\hline Fulminant hepatic failure & $89(10 \%)$ & $118(14 \%)$ & 0.039 & $0.73(0.54-0.98)$ \\
Hepatitis B & $41(5.4 \%)$ & $33(4 \%)$ & 0.27 & $1.29(0.80-1.50)$ \\
Other & $300(36 \%)$ & $318(38 \%)$ & 0.62 & $0.90(0.77-1.10)$ \\
NASH & $4(0.4 \%)$ & $12(1.4 \%)$ & 0.04 & $0.32(0.1-1.0)$ \\
Hepatitis C & $246(28 \%)$ & $223(26 \%)$ & 0.56 & $1.06(0.97-1.30)$ \\
Alcoholic cirrhosis & $183(21 \%)$ & $155(18 \%)$ & 0.10 & $1.20(0.96-1.50)$ \\
\hline
\end{tabular}

Abbreviations: $\mathrm{Cl}$ confidence interval, NASH non-alcoholic steatohepatitis, OLT orthotopic liver transplant, OR odds ratio.

$(\mathrm{p}=0.00001)$. It is important, however, to note that these analyses included patients undergoing RRT, for whom measurement of SCr bore an uncertain temporal relationship to their dialysis. When parameters of renal function were adjusted for patients receiving RRT by assigning them a uniform SCr value of either $4.0 \mathrm{mg} / \mathrm{dL}$ or $5.0 \mathrm{mg} / \mathrm{dL}$, consistent with minimal renal function, then neither $\mathrm{SCr}$ or eGFR retained its correlation with non-recovery of renal function (Table 4). We return to this important issue later (see Tables 8 and 9, and Discussion).

Table 4 Laboratory values in patients with pre-OLT renal dysfunction associated with recovery of renal function post-OLT

\begin{tabular}{|c|c|c|c|}
\hline & Recovery of renal function $(n=863)$ & Non-recovery $(n=857)$ & $\mathrm{p}$ \\
\hline $\mathrm{SCr}$ at time of registration $(\mathrm{mg} / \mathrm{dL})^{*}$ & $2.4 \pm 2.0$ & $2.9 \pm 2.6$ & 0.00001 \\
\hline \multicolumn{4}{|l|}{$\mathrm{SCr}$ at time of registration $(\mathrm{mg} / \mathrm{dL})$} \\
\hline (adjusted for dialysis, $\mathrm{SCr}=4 \mathrm{mg} / \mathrm{dL}$ ) & $2.5 \pm 1.6$ & $2.4 \pm 1.7$ & 0.23 \\
\hline \multicolumn{4}{|l|}{$\mathrm{SCr}$ at time of registration $(\mathrm{mg} / \mathrm{dL})$} \\
\hline (adjusted for dialysis, $\mathrm{SCr}=5 \mathrm{mg} / \mathrm{dL}$ ) & $2.8 \pm 2.0$ & $2.78 \pm 2.0$ & 0.30 \\
\hline SCr at time of transplant & $3.6 \pm 2.0$ & $4.0 \pm 2.3$ & 0.00001 \\
\hline \multicolumn{4}{|l|}{$\mathrm{SCr}$ at time of transplant (mg/dL) } \\
\hline (adjusted for dialysis, $\mathrm{SCr}=4 \mathrm{mg} / \mathrm{dL}$ ) & $3.84 \pm 1.5$ & $3.8 \pm 1.4$ & 0.52 \\
\hline \multicolumn{4}{|l|}{$\mathrm{SCr}$ at time of transplant (mg/dL) } \\
\hline (adjusted for dialysis, $\mathrm{SCr}=5 \mathrm{mg} / \mathrm{dL}$ ) & $4.3 \pm 1.6$ & $4.3 \pm 1.6$ & 0.80 \\
\hline eGFR at time of registration (cc/min) & $57 \pm 41$ & $50 \pm 42$ & 0.00001 \\
\hline \multicolumn{4}{|l|}{ eGFR at time of registration (cc/min) } \\
\hline (adjusted for dialysis, $\mathrm{SCr}=4 \mathrm{mg} / \mathrm{dL}$ ) & $51 \pm 42$ & $53 \pm 44$ & 0.33 \\
\hline \multicolumn{4}{|l|}{ eGFR at time of registration (cc/min) } \\
\hline (adjusted for dialysis $\mathrm{SCr}=5 \mathrm{mg} / \mathrm{dL}$ ) & $51 \pm 43$ & $53 \pm 46$ & 0.33 \\
\hline eGFR at time of transplant (cc/min) & $28 \pm 21$ & $22 \pm 14$ & 0.00001 \\
\hline \multicolumn{4}{|l|}{ eGFR at time of transplant (cc/min) } \\
\hline (adjusted for dialysis, $\mathrm{SCr}=4$ mg/dL) & $20 \pm 14$ & $21 \pm 12$ & 0.30 \\
\hline \multicolumn{4}{|l|}{ eGFR at time of transplant (cc/min) } \\
\hline (adjusted for dialysis, $\mathrm{SCr}=5 \mathrm{mg}$ ) & $19 \pm 14$ & $19 \pm 12$ & 0.49 \\
\hline Serum ALT at time of transplant (units/L) & $257 \pm 888$ & $489 \pm 1379$ & 0.007 \\
\hline INR at time of transplant & $2.1 \pm 1.5$ & $2.2 \pm 2.8$ & 0.80 \\
\hline Total bilirubin at time of transplant (mg/dL) & $14.0 \pm 14.4$ & $16.0 \pm 16.0$ & 0.38 \\
\hline Serum albumin at time of transplant $(\mathrm{g} / \mathrm{dL})$ & $2.78 \pm 0.76$ & $2.82 \pm 0.77$ & 0.18 \\
\hline
\end{tabular}

* For patients receiving RRT, several values of SCr were used, an unadjusted and two adjusted values. The unadjusted SCr was the value entered into the UNOS database. Given uncertainty whether the entered $\mathrm{SCr}$ was obtained pre- or post-dialysis, analysis was repeated using a single adjusted value for SCr of either 4.0 or $5.0 \mathrm{mg} / \mathrm{dL}$.

Abbreviations: ALT alanine transaminase, eGFR estimated glomerular filtration rate, INR international normalized ratio, OLT orthotopic liver transplantation, SCr serum creatinine. 
Table 5 Allograft-associated characteristics of patients with pre-OLT renal dysfunction associated with recovery of renal function post-OLT

\begin{tabular}{|c|c|c|c|c|}
\hline & Recovery of renal function $(n=863)$ & Non-recovery $(n=857)$ & $\mathbf{p}$ & OR $(95 \% \mathrm{Cl})$ \\
\hline Transplanted prior to MELD era & $275(31 \%)$ & $344(40 \%)$ & 0.0001 & $0.69(0.57-0.85)$ \\
\hline Whole organ transplant & $846(98 \%)$ & $846(99 \%)$ & 0.23 & $0.65(0.31-1.21)$ \\
\hline MELD score & $33.7 \pm 8.7$ & $34 \pm 9.2$ & 0.40 & \\
\hline Cold ischemia time (hrs) & $7.6 \pm 3.5$ & $7.7 \pm 3.6$ & 0.98 & \\
\hline Warm ischemia time (mins) & $42 \pm 20$ & $41 \pm 18$ & 0.51 & \\
\hline Allograft dysfunction & $111(13 \%)$ & $303(35 \%)$ & 0.00001 & $0.27(0.21-0.34)$ \\
\hline
\end{tabular}

Abbreviations: $C l$ confidence interval, MELD model end-stage liver disease, $O L T$ orthotopic liver transplantation, $O R$ odds ratio.

Multivariate analysis of factors associated with nonrecovery of renal function post-OLT within the entire cohort

We used forward stepwise logistic regression analysis to determine which variables identified by univariate analyses (Tables 1, 2, 3, 4, 5, 6 and 7) were independent predictors of recovery of renal function (Table 8 ). Independent predictors of recovery of renal function post-OLT, in descending order of coefficient of determination, were absence of hepatic allograft dysfunction, transplantation during the MELD era, female sex of the recipient, decreased donor age, decreased recipient ALT at OLT, decreased recipient BMI at registration, use of anti-thymocyte globulin as induction therapy, and a longer wait time from registration.

\section{Multivariate analysis of factors associated with non- recovery of renal function post-OLT within subgroups stratified according to the need for RRT}

To determine whether the predictors of recovery of renal function varied with the level of renal dysfunction prior to OLT, as well as to address uncertainty in the measurement of $\mathrm{SCr}$ among patients receiving RRT (see Table 4), we performed a subgroup analysis of our cohort. We stratified the cohort into the following 4 groups: (1) recipients with $\mathrm{SCr} \geq 2 \mathrm{mg} / \mathrm{dL}$ at any time while awaiting OLT, but not requiring RRT ( $\mathrm{n}=650)$; (2) recipients requiring RRT at the time of registration, but not at the time of transplant (dialysis at registration only, $\mathrm{n}=178$ ); (3) recipients requiring
RRT at the time of transplant, but not at the time of registration (dialysis at transplant only, $\mathrm{n}=519$ ); (4) recipients requiring RRT at both the time of registration and the time of transplant (dialysis-dependence, $n=373$ ).

For each subgroup, we performed a separate forward stepwise logistic regression analysis using variables found to be significant by univariate analysis (data not shown). The results of the multivariate analysis for each subgroup are summarized in Table 9. Notably, an absence of hepatic allograft dysfunction was an independent predictor of recovery of renal function in all 4 subgroups. Among patients with a $\mathrm{SCr} \geq 2 \mathrm{mg} / \mathrm{dl}$ at any time prior to OLT, but not requiring RRT, an absence of allograft dysfunction was the only independent predictor of recovery. Among patients requiring RRT at registration only, the independent predictors of recovery of renal function, in descending order of coefficient of determination, were absence of hepatic allograft dysfunction and a lower MELD score. Among patients requiring RRT at transplant only, the independent predictors of recovery of renal function, in descending order of coefficient of determination, were an absence of allograft dysfunction, transplantation during the MELD era, use of anti-thymocyte globulin as induction therapy, lack of use of cyclosporine, and lack of use of tacrolimus. The emergence of both antithymocyte globulin induction therapy and lack of use of cyclosporine or tacrolimus as independent predictors suggests that the beneficial effect of anti-thymocyte globulin induction extends beyond its sparing of calcineurin

Table 6 Immunosuppression in patients with pre-OLT renal dysfunction associated with recovery of renal function post-OLT

\begin{tabular}{lllll}
\hline & Recovery of renal function $(\mathbf{n}=\mathbf{8 6 3})$ & Non-recovery $(\mathbf{n}=\mathbf{8 5 7})$ & $\mathbf{p}$ & $\mathbf{O R}(\mathbf{9 5} \% \mathbf{C l})$ \\
\hline Anti-thymocyte globulin induction & $34(4 \%)$ & $16(1.8 \%)$ & 0.014 & $2.15(1.2-4.0)$ \\
OKT3 & $20(2.3 \%)$ & $20(2.3 \%)$ & 0.90 & $0.99(0.53-1.73)$ \\
Basiliximab & $26(3 \%)$ & $32(3.7 \%)$ & 0.69 & $0.80(0.55-1.50)$ \\
Daclizumab & $20(2.3 \%)$ & $31(3.6 \%)$ & 0.27 & $0.74(0.43-1.27)$ \\
Alemtuzumab & $1(0.1 \%)$ & $2(0.2 \%)$ & 0.54 & $0.50(0.44-5.30)$ \\
Cyclosporine & $188(22 \%)$ & $192(22 \%)$ & 0.75 & $0.96(0.76-1.21)$ \\
Tacrolimus & $437(51 \%)$ & $479(56 \%)$ & 0.029 & $0.81(0.67-0.97)$ \\
Sirolimus & $21(3 \%)$ & $23(2.7 \%)$ & 0.74 & $0.87(0.81-1.23)$ \\
\hline
\end{tabular}

Abbreviations: $\mathrm{Cl}$ confidence interval, OLT orthotopic liver transplant, OR odds ratio. 
Table 7 Donor characteristics in patients with pre-OLT renal dysfunction associated with recovery of renal function post-OLT

\begin{tabular}{|c|c|c|c|c|}
\hline & Recovery of renal function $(n=863)$ & Non-recovery $(n=857)$ & $p$ & OR $(95 \% \mathrm{Cl})$ \\
\hline Donor age & $37 \pm 17$ & $39 \pm 17$ & 0.00001 & \\
\hline Donor sex (male) & $542(62 \%)$ & $536(62) \%$ & 1.0 & $1.01(0.87-1.19)$ \\
\hline Donor race (Caucasian) & $611(71 \%)$ & $603(70 \%)$ & 0.9 & $0.94(0.97-1.12)$ \\
\hline Donor BMI & $25.6 \pm 6.1$ & $27.5 \pm 13.0$ & 0.007 & \\
\hline Non-heart-beating donor & $14(1.6 \%)$ & $14(1.6 \%)$ & 0.95 & $1.00(0.47-1.80)$ \\
\hline Donor ALT & $53 \pm 95$ & $59 \pm 158$ & 0.12 & \\
\hline Donor AST & $70 \pm 96$ & $75 \pm 176$ & 0.35 & \\
\hline Donor bilirubin (total) & $1.0 \pm 1.8$ & $1.0 \pm 1.7$ & 0.79 & \\
\hline
\end{tabular}

Abbreviations: ALT alanine transaminase, AST asparatate transaminase, BMI body mass index, Cl confidence interval, OLT orthotopic liver transplant, OR odds ratio.

inhibitor use. Finally, among patients requiring RRT at both registration and transplant, the independent predictors of recovery of renal function, in descending order of coefficient of determination, were an absence of allograft dysfunction, decreased donor age, decreased recipient total bilirubin, and increased donor ALT. With regard to increased donor ALT, the weakest of the predictors, it is noteworthy that, despite statistical difference donor ALT was within the normal range for patients with recovery vs. nonrecovery of renal function.

\section{Analysis of the effect of time on waiting list on post-OLT recovery of renal function}

The duration of renal dysfunction is thought to impact the likelihood of recovery of renal function post-OLT [14]. Even when pre-OLT renal dysfunction is thought to be solely prerenal, prolonged impairment of renal perfusion because of the cirrhotic milieu may lead to slow ischemic dropout of glomeruli and tubules [12]. We therefore analyzed the effect of time on the waiting list among the 4 subgroups of OLT recipients with pre-OLT renal dysfunction.

The mean duration of time on the waiting list did not differ for OLT recipients with recovery vs. non-recovery of renal function for any of the 4 subgroups with preOLT renal dysfunction (Table 10). Remarkably, this was true even for those patients who received RRT both at registration and at OLT $(\mathrm{p}=0.91)$. A recent Consensus Conference on SLKT identified 8 weeks as a threshold duration of RRT beyond which the likelihood of renal recovery was sufficiently low as to justify use of SLKT [15]. We therefore repeated our analysis, restricting our comparison to OLT recipients with wait times $\geq 8$ weeks. We again found no difference in the percentage of patients with recovery vs. non-recovery of renal function for OLT recipients whose wait times exceeded 8 weeks (Table 11). Notably, this includes those recipients requiring RRT at both registration and transplant (Table 11). Thus, among 82 dialysis-dependent patients with wait times of $\geq 8$ weeks, $38(46 \%)$ had recovery of renal function and $44(54 \%)$ had non-recovery $(\mathrm{OR}=1.05,95 \% \mathrm{CI}=0.65-1.75, \mathrm{p}=0.90)$. In fact, recipients receiving RRT at the time of OLT and with a wait time $>8$ weeks had an increased likelihood of recovery vs. non-recovery of renal function (Table 11). Finally, we used Fisher's exact test to compare the likelihood of renal recovery in the subgroup of dialysis-dependent patients, stratified according to whether their wait time was $\leq 8$ weeks vs. $>8$ weeks (Table 12). The percentage of patients having

Table 8 Multivariate analysis of factors independently associated with recovery of renal function post-OLT in all patients with pre-OLT renal dysfunction

\begin{tabular}{llllll}
\hline & Regression coefficient & S.E. & $\mathbf{p}$ & OR (95\% Cl) & Coefficient of determination* \\
\hline Allograft dysfunction & -1.40 & 0.11 & 0.00001 & $0.25(0.18-0.33)$ & 0.047 \\
Transplanted before MELD era & -0.363 & 0.12 & 0.02 & $0.69(0.55-0.87)$ & 0.010 \\
Sex (male) & -0.416 & 0.12 & 0.00001 & $0.66(0.53-0.83)$ & 0.009 \\
Donor age & -0.008 & 0.003 & 0.014 & $0.992(0.986-0.999)$ & 0.007 \\
Recipient ALT at time of transplant & -0.0001 & 0.0001 & 0.026 & $1.0005(1.000-1.001)$ & 0.007 \\
Recipient BMI at time of listing & -0.027 & 0.009 & 0.005 & $0.974(0.95-0.99)$ & 0.005 \\
Anti-thymocyte globulin induction & 0.79 & 0.34 & 0.022 & $2.2(1.12-4.30)$ & 0.004 \\
Wait time from listing (days) & 0.0001 & 0.152 & 0.026 & $1.000(1.000-1.001)$ & 0.004 \\
\hline
\end{tabular}

Abbreviations: $A L T$ alanine transaminase, BMI body mass index, $C I$ confidence interval, MELD model end-stage liver disease, OLT orthotopic liver transplantation, $O R$ odds ratio.

* The cumulative coefficient of determination for all variables combined is 0.093 . 
Table 9 Multivariate analysis of factors independently associated with recovery of renal function post-OLT stratified according to groups

\begin{tabular}{|c|c|c|c|c|c|}
\hline & Regression coefficient & S.E. & $\mathrm{p}$ & OR $(95 \% \mathrm{Cl})$ & Coefficient of variation \\
\hline \multicolumn{6}{|c|}{$\mathrm{SCr} \geq 2 \mathrm{mg} / \mathrm{dL}$, not requiring dialysis $(\mathrm{n}=650)$} \\
\hline Allograft dysfunction & -1.388 & 0.090 & 0.0001 & $0.061(0.163-0.383)$ & 0.11 \\
\hline \multicolumn{6}{|l|}{ Dialysis at registration only } \\
\hline \multicolumn{6}{|l|}{$(n=178)$} \\
\hline Allograft dysfunction & -1.86 & 0.55 & 0.00001 & $0.159(0.054-0.990)$ & 0.119 \\
\hline MELD score & -0.019 & 0.021 & 0.016 & $0.95(0.91-0.99)$ & 0.058 \\
\hline \multicolumn{6}{|l|}{ Dialysis at transplant only } \\
\hline \multicolumn{6}{|l|}{$(n=519)$} \\
\hline Allograft dysfunction & -1.42 & 0.26 & 0.00001 & $0.24(0.14-0.40)$ & 0.084 \\
\hline Transplanted before MELD & -0.83 & 0.21 & 0.00001 & $0.43(0.289-0.670)$ & 0.033 \\
\hline Anti-thymocyte globulin induction & 1.76 & 0.70 & 0.010 & $4.80(1.23-19.10)$ & 0.019 \\
\hline Cyclosporine & -0.77 & 0.27 & 0.030 & $0.46(0.27-0.78)$ & 0.011 \\
\hline Tacrolimus & -0.5 & 0.23 & 0.029 & $0.40(0.40-0.95)$ & 0.011 \\
\hline \multicolumn{6}{|l|}{ Dialysis-dependence } \\
\hline \multicolumn{6}{|l|}{$(n=373)$} \\
\hline Allograft dysfunction & -1.752 & 0.358 & 0.00001 & $0.173(0.086-0.350)$ & 0.139 \\
\hline Donor age & -0.019 & 0.008 & 0.020 & $0.98(0.96-1.0)$ & 0.044 \\
\hline Recipient bilirubin (total) & -0.025 & 0.009 & 0.004 & $0.97(0.96-0.99)$ & 0.040 \\
\hline Donor ALT & 0.008 & 0.003 & 0.020 & $1.008(1.001-1.015)$ & 0.028 \\
\hline
\end{tabular}

Abbreviations: ALT alanine transaminase, BMI body mass index, $C l$ confidence interval, MELD model end-stage liver disease, OLT orthotopic liver transplantation, $O R$ odds ratio, $\mathrm{SCr}$ serum creatinine.

recovery of renal function was the same regardless of wait time ( $45 \%$ for $\leq 8$ weeks vs. $46 \%$ for $>8$ weeks, $p=0.90$ ).

\section{Discussion}

Using the UNOS database, we performed a retrospective analysis to determine factors predictive of recovery of renal function among OLT recipients with pre-OLT renal dysfunction. We defined recovery of renal function as a composite end point of $\mathrm{SCr} \leq 1.5 \mathrm{mg} / \mathrm{dL}$ at discharge and survival $\geq 29$ days. We report several major findings.

First, as in previous studies, recovery of renal function occurred in $~ 50 \%$ of patients with pre-OLT renal dysfunction. This percentage was consistent across all severities of pre-OLT renal function, including patients who required RRT at registration and/or OLT (cf. Figure 1). In accord with our data, Marik et al. reported that 58\% of 28 patients with type I HRS recovered renal function post OLT [6]. Shusterman et al. described post-OLT recovery of renal function in 13 of 17 patients (77\%) with pre-OLT HRS (77\%) and in 8 of 12 (67\%) with pre-OLT acute kidney injury (AKI) [16]. Davis et al. reported that only $1.5 \%$ of patients with severe pre-OLT renal dysfunction (eGFR $<30 \mathrm{ml} / \mathrm{min}$ ) required kidney transplantation within 1 year after OLT, suggesting that recovery of renal function had occurred in a large percentage of these patients [4]. Notably, in the MELD era, for patients requiring RRT at the time of registration, $\sim 15 \%$ of those listed for OLT alone and $\sim 6.5 \%$ of those listed for SKLT no longer required RRT at the time of OLT [4]. Northrup et al., evaluating 1041 patients with pre-OLT renal dysfunction requiring RRT from 2002 to 2007, observed spontaneous renal recovery in $68 \%$ of patients [5]. Finally, in a cohort of 155 patients who received SKLT, Levitsky et al. observed that up to $40 \%$ of patients

Table 10 Wait time in days from listing until OLT in patients with recovery vs. non-recovery of renal function post-OLT grouped by categories of pre-OLT renal dysfunction

\begin{tabular}{llll}
\hline & Recovery of renal function & Non-recovery & $\mathbf{p}$ \\
\hline $\mathbf{S C r} \geq \mathbf{2} \mathbf{~ m g / d L}$, not requiring dialysis $(\mathbf{n}=\mathbf{6 5 0})$ & $363 \pm 233$ & $287 \pm 217$ & 0.51 \\
Dialysis at time of listing $(\mathrm{n}=178)$ & $125 \pm 224$ & $84 \pm 210$ & 0.21 \\
Dialysis at time of transplant $(\mathbf{n}=\mathbf{5 1 9})$ & $251 \pm 182$ & $261 \pm 146$ & 0.16 \\
Dialysis-dependence $(\mathbf{n}=\mathbf{3 7 3})$ & $79 \pm 170$ & $76 \pm 180$ & 0.91 \\
\hline
\end{tabular}


Table 11 Percent of patients with wait time greater than 8 weeks stratified according to recovery vs. non-recovery of renal function post-OLT grouped by categories of pre-OLT renal dysfunction

\begin{tabular}{|c|c|c|c|c|}
\hline & Recovery of renal function & Non-recovery & $\mathrm{p}$ & OR $(95 \% \mathrm{Cl})$ \\
\hline $\begin{array}{l}\mathrm{SCr} \geq 2 \mathrm{mg} / \mathrm{dL} \text {, not requiring dialysis } \\
(\mathrm{n}=391)\end{array}$ & $219(56 \%)$ & $172(44 \%)$ & 0.9 & $1.01(0.84-1.20)$ \\
\hline $\begin{array}{l}\text { Dialysis at time of listing } \\
(n=51)\end{array}$ & $28(55 \%)$ & $23(45 \%)$ & 0.73 & $1.90(0.94-3.50)$ \\
\hline $\begin{array}{l}\text { Dialysis at time of transplant } \\
(n=211)\end{array}$ & $114(54 \%)$ & $97(46 \%)$ & 0.035 & $1.45(1.026-2.07)$ \\
\hline $\begin{array}{l}\text { Dialysis-dependence } \\
(n=82)\end{array}$ & $38(46 \%)$ & $44(54 \%)$ & 0.9 & $1.05(0.65-1.75)$ \\
\hline
\end{tabular}

recovered function of their native kidneys, with postOLT GFR of their native kidneys being in the range of GFR 30 to $40 \mathrm{~mL} / \mathrm{min}$, as assessed by nuclear scanning [17]. Thus, across a broad range of studies, recovery of renal function is a not uncommon occurrence among OLT recipients with pre-OLT renal dysfunction, even those requiring RRT.

Second, the single factor most predictive of renal recovery was an absence of hepatic allograft dysfunction. This was true across all levels of pre-OLT renal dysfunction. Thus, an absence of hepatic allograft dysfunction emerged as the strongest independent predictor of renal recovery not only in our entire cohort of 1720 patients (Table 8), but also in each of our four subgroups of renal dysfunction (Table 9): (1) $\mathrm{SCr} \geq 2 \mathrm{mg} / \mathrm{dL}$ at any time pre-OLT, but not requiring RRT $(\mathrm{n}=650)$; (2) RRT at registration, but not at OLT $(\mathrm{n}=178)$; (3) RRT at OLT, but not at registration $(n=519)$; (4) RRT at both registration and OLT $(n=373)$. Remarkably, in the first subgroup, an absence of allograft dysfunction was the only independent predictor of renal recovery, whereas in the second subgroup it was the stronger of only two independent predictors.

We speculate that hepatic allograft dysfunction may impede recovery of renal function through multiple mechanisms. Possible contributory factors include persistence of the cirrhotic milieu, surgical complications, need for reoperation, and adverse systemic factors associated with allograft dysfunction, such as vascular thrombosis, reperfusion syndrome, hemorrhage, inflammation, or infection [18,19]. Such factors may not only prevent recovery of renal function post-OLT, but also lead to superimposed AKI. Indeed, several studies have observed a strong association between hepatic allograft dysfunction and post-OLT renal dysfunction and/or need for RRT $[19,20]$.

Other predictors of post-OLT recovery of renal function, identified within our entire cohort or within one or more of our subgroups, may also relate indirectly to allograft dysfunction. For example, our study concurs with others in showing a worse outcome with the use of older donors [5,21,22] (Tables 8 and 9). While the mechanism for the detrimental effect of older donor age on renal recovery is not fully understood, a slower onset of hepatic allograft function may be contributory [23,24]. There is also evidence that the livers from older donors are at greater risk for ischemia-reperfusion injury [25-27], although there is no universal agreement on this point [28]. Transplantation within the MELD era was also associated with a greater likelihood of post-OLT renal recovery. We observed this in the entire cohort (Table 8) and in the subgroup requiring RRT at OLT only (Table 9). Advantages within the MELD era include improved surgical technique and peri-transplant management, both leading to improved allograft function [18,29-33]. We cannot, however, exclude other beneficial aspects of the MELD era, such as minimization of nephrotoxic immunosuppression and earlier transplantation of patients with pre-OLT renal dysfunction, especially those requiring RRT [34-36].

Third, most of the remaining predictors of renal recovery relate either to the severity of the recipient's liver disease or to the choice of immunosuppressive regimen post-OLT. Thus, within our entire cohort (Table 8), or within one or more subgroups (Table 9), independent predictors of renal recovery included a lower recipient MELD score, a

Table 12 Recovery of renal function among dialysis-dependent recipients of OLT stratified according to wait time greater than or less than 8 weeks

\begin{tabular}{lllll}
\hline & Recovery of renal function $(\mathbf{n = 1 6 9 )}$ & Non-recovery $(\mathbf{n}=\mathbf{2 0 4})$ & $\mathbf{p}$ & OR $(\mathbf{9 5 \%} \mathbf{C l})$ \\
\hline $\begin{array}{l}\text { Wait time }>8 \text { weeks } \\
(\mathrm{n}=82)\end{array}$ & $38(46 \%)$ & $44(54 \%)$ & 0.90 & $1.05(0.65-1.75)$ \\
Wait time $\leq 8$ weeks & $131(45 \%)$ & $160(55 \%)$ & 0.87 & $1.025(0.80-1.30)$ \\
$(\mathrm{n}=291)$ & & &
\end{tabular}

Abbreviations: $\mathrm{Cl}$ confidence interval, OLT orthotopic liver transplantation, $\mathrm{OR}$ odds ratio, $\mathrm{SCr}$ serum creatinine. 
decreased recipient total bilirubin, and a decreased recipient ALT. A decreased recipient BMI was also an independent predictor of renal recovery, and may reflect the absence of ascites. Alternatively, an increased recipient BMI may reflect obesity rather than ascites. In this case, renal recovery may be impaired because of obesity-associated inflammatory responses or an increased risk for a smallfor-size allograft with resultant allograft dysfunction and renal hypoperfusion $[37,38]$.

With respect to the immunosuppressive regimen, lack of use of cyclosporine or tacrolimus emerged as an independent predictor of renal recovery. This is most likely because of renal hypoperfusion and other potentially nephrotoxic effects associated with use of calcineurin inhibitors [39]. Patients not treated with a calcineurin inhibitor tended to receive sirolimus. Thus, of 434 patients who did not receive a calcineurin inhibitor, 417 (96\%) received sirolimus; correspondingly, of 1286 patients who received a calcineurin inhibitor, only $27(2 \%)$ received sirolimus $(\mathrm{p}=0.057)$.

One of the more intriguing findings of our study is the possibly beneficial effect of anti-thymocyte globulin induction, which emerged as independent predictor of renal recovery within our entire cohort (Table 8) and among patients requiring RRT at the time of OLT (Table 9). The most obvious benefit of anti-thymocyte globulin induction lies in the fact that its use permits minimization of the dose of calcineurin inhibitors [40]. However, there may be additional more direct benefits, as suggested by the fact that failure to use calcineurin inhibitors and administration of anti-thymocyte globulin induction were retained as independent predictors in our multivariate analysis. In addition to the prominent $\mathrm{T}$ cell-depleting effects of anti-thymocyte globulin, this polyclonal antibody binds to and neutralizes multiple antigens present not only on $\mathrm{T}$ cells but also on neutrophils and other inflammatory cells, particularly adhesion molecules and chemokine receptors, both of which are involved in the recruitment of inflammatory cells to areas of ischemia-reperfusion injury [40]. Finally, anti-thymocyte globulin may have increased the likelihood of renal recovery by minimizing the occurrence of acute allograft rejection. Several facts argue against this. The incidence of acute allograft rejection was very low overall, and not different in patients who received anti-thymocyte globulin versus those who did not anti- ( $0 \%$ vs. $0.8 \%, \mathrm{p}=1.00)$. Moreover, on univariate analysis, the absence of an acute rejection episode failed to predict renal recovery $(\mathrm{p}=0.77)$.

Finally, in contrast to some studies [4,13-15], our data suggest that among patients with pre-OLT renal dysfunction a shorter duration of time on the transplant list is not an independent predictor of post-OLT renal recovery. Indeed, for the entire cohort, a longer, and not a shorter, wait time predicted renal recovery (Table 8). Notably, when we restricted our analysis to patients who required RRT at both registration and OLT, and were therefore presumably dialysis-dependent, we observed the following. Neither the mean wait time (Table 10) nor the percentage of patients with wait times $>8$ weeks (Table 11) was statistically different for recipients recovering renal function vs. those lacking renal recovery (Table 10). Moreover, the percentage of dialysis-dependent patients with post-OLT recovery of renal function was virtually the same in recipients with wait times greater than 8 weeks vs. less than 8 weeks ( $46 \%$ vs. $45 \%$ ). These data highlight the importance of the cirrhotic milieu in compromising renal function, and suggest that reversible prerenal factors may predominate for prolonged periods of times, even lengths of time typically thought to be indicative of chronic irreversible renal damage.

With respect to the length of time on RRT, several considerations may bear on the discrepancy between our results and those of previous studies. Patients with longer wait times may be healthier and able to survive longer until receiving an OLT. In addition, since the need for RRT was recorded only at registration and transplantation, we cannot be sure that dialysis-dependent patients required RRT for the entire intervening period. This point requires further study. In support of our findings, Machicao et al. reported a negative association between an elevated $\mathrm{SCr}$ pre-OLT and the development of progressive renal dysfunction post-OLT, suggesting recovery of renal function in these patients postOLT [36]. In contrast, Bahirwani et al. found that the duration of renal dysfunction and the presence of pre-OLT diabetes mellitus were inversely correlated with postOLT improvement and preservation of renal function [13]. Others studies have also suggested that a longer duration of pre-OLT renal dysfunction is a risk factor for non-recovery of renal function $[6,14]$. It is pertinent to note that some studies in which native kidney function was evaluated following OLT have observed recovery of native kidney function after protracted periods of time, between 75 and 365 days $[6,17,41]$.

Our study has a number of strengths. The most important is our use of the UNOS database, containing prospective data from over 100 centers over a period of $>20$ years. An additional strength is the large size of our cohort, which is greater than that of previous studies [13,14]. In addition, we used a rigorous definition of recovery of renal function, requiring a composite endpoint of survival $\geq 29$ days plus a $\mathrm{SCr} \leq 1.5 \mathrm{mg} / \mathrm{dL}$ at discharge. Finally, we evaluated predictors of renal recovery not only in the entire cohort, but also in several subgroups of patients with varying degrees of pre-OLT renal dysfunction.

We note several limitations to our study. First, the retrospective nature of our study limited our ability to acquire data, for example, the requirement for intra-operative transfusion or vasopressors. Second, the UNOS database 
contains information only at specified time points, so we were unable to determine the exact duration of pre-OLT renal dysfunction. Third, we lacked information on the etiology of pre-OLT renal dysfunction. The distinction between pre-renal and renal causes is especially critical in patients with liver failure. Post-OLT recovery of renal function is more likely for patients whose renal dysfunction is attributable to reversible pre-renal factors from the cirrhotic milieu, and less likely for patients whose renal dysfunction results from intrinsic factors attributable to chronic irreversible damage. Finally, we used the MDRD formula to determine eGFR. While estimates of renal function in cirrhotic patients based on SCr are known to overestimate the true GFR, it is important to emphasize that our analysis was limited to the correlation between renal recovery and changes, rather than absolute levels, of eGFR.

\section{Conclusion}

In summary, our study suggests that the most important independent predictor of renal recovery in OLT recipients is the absence of hepatic allograft dysfunction. The immunosuppressive regimen appears also to be important, with avoidance of calcineurin inhibitors and use of anti-thymocyte globulin induction both associated with post-OLT recovery of renal function. Importantly, the mechanism of action of anti-thymocyte globulin induction appears to be distinct from that of calcineurin inhibitor sparing. Our study further suggests that reversible prerenal factors attributable to the cirrhotic milieu play a major etiologic role in approximately $50 \%$ of patients with re-OLT renal dysfunction. Our data also indicate that the duration of renal dysfunction, even among those requiring RRT, is a poor way to discriminate reversible from irreversible renal dysfunction. Given the scarcity of organs available for SLKT, a clear need exists for additional studies, incorporating renal biopsy data. These studies will help not only to determine which patients should receive SLKT rather than OLT alone, but also to identify peritransplant regimens that enhance the likelihood of post-OLT renal recovery.

\section{Competing interests}

The authors declare that they have no competing interests. No external funding supported this research.

\section{Authors' contributions \\ $J \mid l$ is the Principal Investigator, and participated in study design, statistical analysis, manuscript creation and preparation, data management, and review of the literature. EF: participated in study design, review of the literature, and copy editing of the manuscript. SM participated in study design and review of the literature. JMD participated in study design, review of the literature, and statistical analysis. JSL is the Senior investigator, and participated in study design, statistical analysis, manuscript editing and preparation, and review of the literature. All authors read and approved the final manuscript and its revisions.}

\section{Acknowledgements}

This work is based on Organ Procurement and Transplant Network (OPTN) data from March, 2005, and was supported in part by Health Resources and Services Administration contract 231-00115. The content is the responsibility of the authors and does not necessarily reflect the views or policies of the Department of Health and Human Services, nor does mention of trade names, commercial products, or organizations imply endorsement by the $U$. S. Government.

\section{Author details}

${ }^{1}$ Department Medicine subsection of Nephrology, UMDNJ School of Osteopathic Medicine, Stratford, NJ 08084, USA. ²Department of Medicine subsection Nephrology, Jersey Shore University Medical Center Neptune, Neptune, NJ, USA. ${ }^{3}$ Robert Wood Johnson School of Medicine, New Brunswick, NJ, USA. ${ }^{4}$ Department of Medicine, Jersey Shore University Medical Center, Neptune, NJ, USA. 'Department of Surgery, Jersey Shore University Medical Center, Neptune, NJ, USA. ${ }^{6}$ Department of Medicine, Section of Nephrology, University of Illinois at Chicago, Chicago, IL 60612, USA. ${ }^{7}$ Jesse Brown Veterans Affairs Medical Center, Chicago, IL 60612, USA.

Received: 20 October 2012 Accepted: 8 July 2013

Published: 13 July 2013

\section{References}

1. Davis CL, Gonwa TA, Wilkinson AH: Pathophysiology of renal disease associated with liver disorders: implications for liver transplantation. Part I Liver Transp/ 2002, 8:91-9109.

2. Fagundes C, Ginès P: Hepatorenal syndrome: a severe, but treatable, cause of kidney failure in cirrhosis. Am J Kidney Dis 2012, 59:874-885.

3. Gonwa TA, McBride MA, Anderson K, Mai ML, Wadei H, Ahsan N: Continued influence of preoperative renal function on outcome of orthotopic liver transplant (OLTX) in the US: where will MELD lead us? Am J Transplant 2006, 6:2651-2659.

4. Davis CL, Feng S, Sung R, Wong F, Goodrich NP, Melton LB, Reddy KR, Guidinger MK, Wilkinson A, Lake J: Simultaneous liver-kidney transplantation: evaluation to decision making. Am J Transplant 2007, 7:1702-1709.

5. Northup PG, Argo CK, Bakhru MR, Schmitt TM, Berg CL, Rosner MH: Pretransplant predictors of recovery of renal function after liver transplantation. Liver Transpl 2010, 16:440-446.

6. Marik PE, Wood K, Starzl TE: The course of type 1 hepato-renal syndrome post liver transplantation. Nephrol Dial Transplant 2006, 21:478-482.

7. Pham PT, Pham PC, Wilkinson AH: Renal function outcomes following liver transplantation and combined liver-kidney transplantation. Nat Clin Pract Nephrol 2007, 3:507-514.

8. Wong F, Nadim MK, Kellum JA, Salerno F, Bellomo R, Gerbes A, Angeli P, Moreau R, Davenport A, Jalan R, Ronco C, Genyk Y, Arroyo V: Working Party proposal for a revised classification system of renal dysfunction in patients with cirrhosis. Gut 2011, 60:702-709.

9. Francoz C, Durand F: A new look at renal dysfunction in the cirrhotic patient. Crit Care 2012, 16:118.

10. Nadim MK, Kellum JA, Davenport A, Wong F, Davis C, Pannu N, Tolwani A, Bellomo R, Genyk YS: Epatorenal syndrome: the 8th international consensus conference of the Acute Dialysis Quality Initiative (ADQI) Group. Crit Care 2012, 16:1-R23.

11. Wadei HM, Geiger XJ, Cortese C, Mai ML, Kramer DJ, Rosser BG, Keaveny AP, Willingham DL, Ahsan N, Gonwa TA: Kidney allocation to liver transplant candidates with renal failure of undetermined etiology: role of percutaneous renal biopsy. Am J Transplant 2008, 8:2618-2626.

12. Trawalé JM, Paradis V, Rautou PE, Francoz C, Escolano S, Sallée M, Durand F, Valla $D$, Lebrec D, Moreau R: The spectrum of renal lesions in patients with cirrhosis: a clinicopathological study. Liver Int 2010, 30:725-732.

13. Bahirwani R, Campbell MS, Siropaides T, Markmann J, Olthoff K, Shaked A, Bloom RD, Reddy KR: Transplantation: impact of pretransplant renal insufficiency. Liver Transp/ 2008, 14:665-671.

14. Campbell MS, Kotlyar DS, Brensinger CM, Lewis JD, Shetty K, Bloom RD, Markmann JF, Olthoff KM, Shaked A, Reddy KR: Renal function after orthotopic liver transplantation is predicted by duration of pretransplantation creatinine elevation. Liver Transp/ 2005, 11:1048-1055.

15. Eason JD, Gonwa TA, Davis CL, Sung RS, Gerber D, Bloom RD: Proceedings of Consensus Conference on Simultaneous Liver Kidney Transplantation (SLK). Am J Transplant 2008, 8:2243-2251.

16. Shusterman B, Mchedishvili G, Rosner MH: Outcomes for hepatorenal syndrome and acute kidney injury in patients undergoing liver transplantation: a singlecenter experience. Transplant Proc 2007, 39:1496-1500. 
17. Levitsky J, Baker T, Ahya SN, Levin ML, Friedewald J, Gallon L, Ho B, Skaro A, Krupp J, Wang E, Spies SM: Salomon DR. Abecassis MM: Outcomes and Native Renal Recovery Following Simultaneous Liver-Kidney Transplantation. Am J Transplant; 2012.

18. Feltracco P, Barbieri S, Galligioni H, Michieletto E, Carollo C, Ori C: Intensive care management of liver transplanted patients. World J Hepatol 2011, 3:61-71.

19. Cabezuelo JB, Ramírez P, Ríos A, Acosta F, Torres D, Sansano T, Pons JA, Bru M, Montoya M, Bueno FS, Robles R, Parrilla P: Risk factors of acute renal failure after liver transplantation. Kidney Int 2006, 69:1073-1080.

20. Bilbao I, Charco R, Balsells J, Lazaro JL, Hidalgo E, Llopart L, Murio E, Margarit C: Risk factors for acute renal failure requiring dialysis after liver transplantation. Clin Transplant 1998, 12:123-129.

21. Hoofnagle JH, Lombardero M, Zetterman RK, Lake J, Porayko M, Everhart J, Belle SH, Detre KM: Donor age and outcome of liver transplantation. Hepatology 1996, 24:89-96.

22. Macedo FI, Miranda LE, Fernandes JL, Pádua TC, Figueroa JN, Neto OL, Lacerda CM: Donor age as a predictor of risk for short-term outcomes after liver transplant. Exp Clin Transplant 2010, 8:202-209.

23. Yersiz H, Shaked A, Olthoff $K$, Imagawa D, Shackleton C, Martin P, Busuttil RW: Correlation between donor age and the pattern of liver graft recovery after transplantation. Transplantation 1995, 60:790-794.

24. Tanemura A, Mizuno S, Wada H, Yamada T, Nobori T, Isaji S: Donor age affects liver regeneration during early period in the graft liver and late period in the remnant liver after living donor liver transplantation. World J Surg 2012, 36:1102-1111.

25. Selzner M, Selzner N, Chen L, Borozan I, Sun J, Xue-Zhong M, Zhang J, McGilvray ID: Exaggerated up-regulation of tumor necrosis factor alphadependent apoptosis in the older mouse liver following reperfusion injury: targeting liver protective strategies to patient age. Liver Transp/ 2009, 15:1594-1604.

26. Zaman MB, Leonard MO, Ryan EJ, Nolan NP, Hoti E, Maguire D, Mulcahy H, Traynor O, Taylor CT, Hegarty JE, Geoghegan JG, O'Farrelly C: Lower expression of Nrf2 mRNA in older donor livers: a possible contributor to increased ischemia-reperfusion injury? Transplantation 2007, 84:1272-1278.

27. Deschênes M, Forbes C, Tchervenkov J, Barkun J, Metrakos P, Tector J, Alpert $\mathrm{E}$ : Use of older donor livers is associated with more extensive ischemic damage on intraoperative biopsies during liver transplantation. Liver Transp/ Surg 1999, 5:357-361.

28. Martins PN, Chang S, Mahadevapa B, Martins AB, Sheiner P: Liver grafts from selected older donors do not have significantly more ischaemia reperfusion injury. HPB (Oxford) 2011, 13:212-220.

29. Massicotte L, Denault AY, Beaulieu D, Thibeault L, Hevesi Z, Nozza A Lapointe R, Roy A: Transfusion Rate for 500. Experience of One Liver Transplantation Center. Transplantation: Consecutive Liver Transplantations; 2012.

30. Gluud LL, Christensen K, Christensen E, Krag A: Systematic review of randomized trials on vasoconstrictor drugs for hepatorenal syndrome. Hepatology 2010, 51:576-584

31. Krag A, Møller S, Henriksen JH, Holstein-Rathlou NH, Larsen FS, Bendtsen F: Terlipressin improves renal function in patients with cirrhosis and ascites without hepatorenal syndrome. Hepatology 2007, 46:1863-1871.

32. Massicotte L, Lenis S, Thibeault L, Sassine MP, Seal RF, Roy A: Effect of low central venous pressure and phlebotomy on blood product transfusion requirements during liver transplantations. Liver Transp/ 2006, 12:117-123.

33. Massicotte L, Sassine MP, Lenis S, Seal RF, Roy A: Survival rate changes with transfusion of blood products during liver transplantation. Can $J$ Anaesth 2005, 52:148-155.

34. Douthitt L, Bezinover D, Uemura T, Kadry Z, Shah RA, Ghahramani N, Janicki PK: Perioperative use of continuous renal replacement therapy for orthotopic liver transplantation. Transplant Proc 2012, 44:1314-1317.

35. Feng ZZ, Tang J, Kim DY, Brown K, Abouljoud M, Gordon S, Yoshida A Huang MA, Divine G, Moonka DK: Renal insufficiency after liver transplantation in the MELD era compared to the pre-MELD era. Clin Transplant 2009, 23:637-642.

36. Machicao VI, Srinivas TR, Hemming AW, Soldevila-Pico C, Firpi RJ, Reed Al, Morelli GJ, Nelson DR, Abdelmalek MF: Impact of implementation of the MELD scoring system on the prevalence and incidence of chronic renal disease following liver transplantation. Liver Transp/ 2006, 12:754-761.

37. Fukazawa K, Nishida S, Volsky A, Tzakis AG, Pretto EA: Body surface area index predicts outcome in orthotopic liver transplantation. $J$ Hepatobiliary Pancreat Sci 2011, 18:216-225.
38. Cave MC, Hurt RT, Frazier TH, Matheson PJ, Garrison RN, McClain CJ, McClave SA: Obesity, inflammation, and the potential application of pharmaconutrition. Nutr Clin Pract 2008, 23:16-34

39. Ziolkowski J, Paczek L, Senatorski G, Niewczas M, Oldakowska-Jedynak U, Wyzgal J, Sanko-Resmer J, Pilecki T, Zieniewicz K, Nyckowski P, Patkowski W, Krawczyk M: Renal function after liver transplantation: calcineurin inhibitor nephrotoxicity. Transplant Proc 2003, 35:2307-2309.

40. Mehrabi A, Mood Z, Sadeghi M, Schmied BM, Müller SA, Welsch T, Kuttymuratov G, Wente MN, Weitz J, Zeier M, Morath C, Riediger C, Schemmer P, Encke J, Büchler MW, Schmidt J, Riediger C, Schemmer P, Encke J, Büchler MW, Schmidt J: Thymoglobulin and ischemia reperfusion injury in kidney and liver transplantation. Nephrol Dial Transplant 2007, 22(Suppl 8):viii54-viii60.

41. Francis JM, Palmer MR, Donohoe K, Curry M, Johnson SR, Karp SJ, Evenson AR, Pavlakis M, Hanto DW, Mandelbrot DA: Evaluation of native kidney recovery after simultaneous liver-kidney transplantation. Transplantation 2012, 93:530-535.

doi:10.1186/1471-2369-14-147

Cite this article as: Iglesias et al:: Predictors of renal recovery in patients with

pre-orthotopic liver transplant (OLT) renal dysfunction. BMC Nephrology $201314: 147$.

\section{Submit your next manuscript to BioMed Central and take full advantage of:}

- Convenient online submission

- Thorough peer review

- No space constraints or color figure charges

- Immediate publication on acceptance

- Inclusion in PubMed, CAS, Scopus and Google Scholar

- Research which is freely available for redistribution 